Article

\title{
The Blood Lactate Increase in High Intensity Exercise Is Depressed by Acanthopanax sieboldianus
}

\author{
Morimasa Kato ${ }^{1}$, Shizue Kurakane ${ }^{1}$, Atsuyoshi Nishina ${ }^{1}$, Jaeyoung Park ${ }^{2}$ and Hyukki Chang ${ }^{3, *}$ \\ 1 Department of Health and Nutrition, Yonezawa Women's Junior College of Yamagata Prefecture, \\ Yonezawa 992-0025, Japan; E-Mails: m-kato@yone.ac.jp (M.K.); kurakane@yone.ac.jp (S.K.); \\ nishina.atsuyoshi@nihon-u.ac.jp (A.N.) \\ 2 Department of Sport, Kyungil University, Gyeongsan, Gteongbuk 712-701, Korea; \\ E-Mail: sports@kiu.ac.kr
}

3 Department of Human Movement Science, Seoul Women's University, 621 Hwarangro, Nowon-Gu, Seoul 139-774, Korea

* Author to whom correspondence should be addressed; E-Mail: hkchang@swu.ac.kr; Tel.: +82-2-970-5689; Fax: +82-2-970-5980.

Received: 1 July 2013; in revised form: 9 September 2013 / Accepted: 23 September 2013 / Published: 16 October 2013

\begin{abstract}
This study investigates the anti-fatigue effects of Acanthopanax sieboldianus (A. sieboldianus) at various exercise intensities. Two experiments were conducted in 18 Sprague-Dawley rats. In Experiment 1, a three-stage increment test $(15 \mathrm{~m} / \mathrm{min}$ for $5 \mathrm{~min}$, and $20 \mathrm{~m} / \mathrm{min}$ for $5 \mathrm{~min}$ and $25 \mathrm{~m} / \mathrm{min}$ for $10 \mathrm{~min}$ ) was performed using a treadmill. In Experiment 2, a 10-min swimming test was conducted. Blood samples were extracted from each rat before, during and after the exercises and the blood concentrations of lactate and glucose measured. In both experiments, water (control) or A. sieboldianus solution (ASS) was administered orally using a zonde $30 \mathrm{~min}$ before the exercise. In the swimming test, ASS administration significantly decreased the blood lactate level measured at the end of the exercise and $5 \mathrm{~min}$ post-exercise relative to the water group, although the two groups did not differ significantly in the treadmill test. Our study demonstrates that a single oral administration of $A$. sieboldianus prior to high-intensity exercise significantly decreases the blood lactate concentration suggesting that $A$. sieboldianus has an intrinsic anti-fatigue effect.
\end{abstract}

Keywords: Acanthopanax sieboldianus; running; swimming; blood lactate; fatigue 


\section{Introduction}

Previous research has shown that regular physical activity and proper diet are important not only for preventing lifestyle-related diseases but also for promoting and maintaining one's health [1-3]. In recent years, dietary supplements have attracted interest in the expectation that the individual or synergistic effects of their components might alleviate social health problems such as metabolic syndromes and stress-induced psychiatric disorders. Previous studies have shown that Acanthopanax sieboldianus (A. sieboldianus), a member of the Araliaceae family, has antioxidant effects and suppresses the postprandial rise in the blood glucose levels [4,5].

A. senticosus Harms (Siberian ginseng) is another member of the Araliaceae family, and has long been used as a nourishing tonic. Ingestion of $A$. senticosus Harms influences the central nervous system, causing euphoria, increasing alertness, and improving concentration levels [6]. Additionally, A. senticosus Harms has been reported to exert anti-stress effects in rats subjected to water immersion restraint stress and has also been reported to prevent gastric ulcers [7]. A common pathway involves the activation of the brain monoamine and gamma-aminobutyric acid (GABA) system, which activates the metabolism of dopamine, noradrenaline, and serotonin in the cortex and the hypothalamus. These neurotransmitters are also closely related to exercise performance. Accordingly, a recent study in which mice were subjected to swimming exercise reported that ingestion of $A$. senticosus extracts enhanced the animals' endurance capacity, which suggests that this substance also exerts an anti-fatigue effect during exercise [8].

On the basis of these findings, we proposed a hypothesis that $A$. sieboldianus also exerts an anti-fatigue effect during exercise. It is essential to consider the relationship between exercise and nutritional intake specifically the different physiological responses induced by exercise at various intensities [9]. The upper limit of the workload that can be sustained by aerobic metabolism is known as the Anaerobic Threshold (AT), and the responses of hormonal and ventilation parameters during exercise change at the AT boundary [10,11]. In this study, we performed an incremental treadmill running test at different levels of exercise intensity, including intensities above and below the anaerobic threshold and a swimming test to examine the effects of $A$. sieboldianus intake on the changes in the blood lactate and glucose concentrations during and after exercise.

\section{Experimental Section}

\subsection{Animals}

Adult male Sprague-Dawley rats $(n=18)$ weighing between 230 and $260 \mathrm{~g}$ were obtained from CLEA, Japan, Inc. (Tokyo, Japan). All animals were housed in group cages illuminated from 08:00 to 20:00 (12:12-h cycle) at a breeding-appropriate temperature between 21 and $23{ }^{\circ} \mathrm{C}$. Throughout the experiment, the animals received commercial rodent chow CE2 (CLEA Japan Inc., Tokyo, Japan) and water ad libitum. All rats were housed under laboratory conditions for 1 week for environmental adaptation. All procedures were performed in accordance with the Institutional Guidelines for Animal Care as specified by the National Institutes of Health Guidelines for the Care and Use of Laboratory Animals. The use of animals was reviewed and approved by the Animal Care Review Committee at Yonezawa Women's Junior College of Yamagata Prefecture. The habituation protocol was performed 
to acclimate the rats to running on the treadmill by exercising them on the treadmill for $30 \mathrm{~min}$ 5 times a week, with a gradual increase in velocity (from $10 \mathrm{~m} / \mathrm{min}$ initially to $25 \mathrm{~m} / \mathrm{min}$ by the end) to allow adaptation. At the end of the treadmill running habituation, a silicone catheter was inserted into each rat's jugular vein to allow blood sampling during exercise, as previously described $[12,13]$. Both treadmill habituation and sampling were performed between 09:00 and 12:00. The rats were weighed before and every day after treadmill habituation, and all experiments were performed after every animal had recovered its full pre-habituation body weight. Preliminary experiments indicated that after treadmill habituation, the subjects' blood lactate levels did not change from their resting levels when the animals were placed on the treadmill. This study did not include a non-exercise group as a control for the changes in the blood lactate level during exercise.

\subsection{Experiment 1: Treadmill Running Test Protocol}

Twelve hours before the experiment, the rats were fasted by removing the chow to minimize the effect of food consumption just prior to the measurements on the blood glucose level. In this experiment, the rats $(n=6)$ were randomly assigned to receive water or $A$. sieboldianus solution (ASS) via zonde on the first day of the experiment and the alternative treatment on the second day. Thirty min after administration of water or ASS $(0.15 \mathrm{~g} / \mathrm{kg}, 1 \mathrm{~mL})$, each rat was forced to run a treadmill program with an incrementally increasing speed ( 15 to 20 to $25 \mathrm{~m} / \mathrm{min}$ ) for a total of $20 \mathrm{~min}$ once a day for 2 days. The speed equivalent to the AT in rats is approximately $20 \mathrm{~m} / \mathrm{min}$ [13]. In this experiment, the rats ran at 20 or $25 \mathrm{~m} / \mathrm{min}$ for a total of $10 \mathrm{~min}$. This intensity is equivalent to approximately $60 \%$ to $70 \%$ of maximum oxygen consumption $\left(\mathrm{VO}_{2 \mathrm{max}}\right)$. At various time-points (pre-exercise, 5, 10, 15, and $20 \mathrm{~min}$ into the exercise, and after $5 \mathrm{~min}$ of recovery), $10-\mu \mathrm{L}$ venous blood samples were taken for measurement of lactate and glucose. After the experiment, the rats were returned to their cages.

\subsection{Experiment 2: Swimming Exercise Test Protocol}

The rats were divided into a water-ingestion group $(n=6)$ and an ASS-ingestion group $(n=6)$. The rats in each group were forced to swim in a round-shaped pool filled with tap water under the following conditions: duration $=10 \mathrm{~min}$, temperature $=35-37^{\circ} \mathrm{C}$, diameter $=46 \mathrm{~cm}$, depth $=40 \mathrm{~cm}$. At the end of the 10-min swimming stress protocol, venous blood samples were taken from the jugular catheters while the rats were still in the pool. The rats were then dried and returned to their cages. Blood samples for measurement of lactate and glucose were obtained at post 5 and $10 \mathrm{~min}$ after the rats were returned to their cages.

\subsection{Lactate and Glucose}

The lactate (Lactate pro, Arkray, Kyoto, Japan) and glucose (Glutestace GT-1640, Arkray, Kyoto, Japan) concentrations of the whole blood samples were measured using the indicated measurement equipments. The intra-assay coefficients of variance for the blood lactate and glucose concentrations were $3.45 \%$ and $3.62 \%$ and the inter-assay coefficients of variance were $3.98 \%$ and $3.13 \%$, respectively, in this study. 
The blood samples were taken before, during $(5,10,15$, and 20 min into the exercise), and 5 min after the treadmill exercise, and before, during (10 min into the exercise), and 5 and $10 \mathrm{~min}$ after the swimming exercise. At least $10 \mu \mathrm{L}$ of blood was taken from the jugular vein catheter before each increasing in the treadmill velocity for measurement of the blood lactate and glucose levels. In addition, the figures of blood lactate and glucose concentrations at each time-point and the time of measurement were plotted and the AUC (Area Under the Curve) values calculated using waveform analysis software (BIMUTAS II. Kissei Comtec, Nagano, Japan) for quantification of the total volume.

\subsection{Statistical Analysis}

All of the data are represented as the mean \pm standard error of the mean (SEM). The effects of the variables were analyzed with a $2 \times 2$ repeated-measures analysis of variance (ANOVA) using the IBM SPSS 20 statistical package. If significant effects or interactions were confirmed, the Tukey post-hoc test was used to determine the significant differences. In experiment 1 , treadmill habituation was necessary to train the rats to run on treadmill, which would have made it difficult and time-consuming to use separate ASS and control groups in a crossover design and the two groups were compared using paired $t$-tests. As experiment 2 involved only the first swimming experience of all of the rats, two different groups were set up and evaluated. Therefore, the Mann-Whitney U test, an unpaired test, was used for analysis. In addition, the effect size and power were calculated for each statistic. Statistical significance was accepted at the level of $p<0.05$.

\section{Results}

\subsection{Incremental Treadmill Test-Blood Lactate}

The results of 2-way ANOVA were $(F(1,34)=0.33, p=0.57, \operatorname{ES}(f)=0.10$, power $=0.13)$ for the condition (ASS vs. water), $(F(5,34)=4.71, p<0.01, \mathrm{ES}(f)=0.83$, power $=1.00)$ for the time course, and $(F(5,34)=0.56, p=0.71, \operatorname{ES}(f)=0.29$, power $=0.39)$ for the condition $\times$ time course, indicating that the blood lactate level changed significantly over the time course.

The blood lactate concentrations after administration of ASS were $1.06 \pm 0.12 \mathrm{mM}$ at rest, $0.71 \pm 0.01 \mathrm{mM}$ at $5 \mathrm{~min}$ after the start of exercise, $1.20 \pm 0.27 \mathrm{mM}$ at $10 \mathrm{~min}$ after the start of exercise, $1.55 \pm 0.40 \mathrm{mM}$ at $15 \mathrm{~min}$ after the start of exercise, $1.68 \pm 0.41 \mathrm{mM}$ at $20 \mathrm{~min}$ after the start of exercise and $1.25 \pm 0.26 \mathrm{mM}$ at $5 \mathrm{~min}$ post-exercise. There was no significant change over the time course (Figure 1A). The values after administration of water were $0.82 \pm 0.07 \mathrm{mM}$ at rest, $0.83 \pm 0.09 \mathrm{mM}$ at $5 \mathrm{~min}$ after the start of exercise, $0.94 \pm 0.08 \mathrm{mM}$ at $10 \mathrm{~min}$ after the start of exercise, $1.38 \pm 0.14 \mathrm{mM}$ at $15 \mathrm{~min}$ after the start of exercise, $1.54 \pm 0.23 \mathrm{mM}$ at $20 \mathrm{~min}$ after the start of exercise and $1.23 \pm 0.12 \mathrm{mM}$ at $5 \mathrm{~min}$ post exercise. The blood lactate concentration was significantly higher $20 \mathrm{~min}$ after the start of exercise than at rest (Figure 1A).

The AUC did not differ significantly between the ASS and control conditions (ASS: $27.4 \pm 3.7 \mathrm{mM} \times \min$, control: $25.2 \pm 2.9 \mathrm{mM} \times \min , p=0.528, \mathrm{ES}(d)=0.69$, power $=0.28)($ Figure $1 \mathrm{~B})$. 
Figure 1. Changes in the blood lactate on incremental treadmill exercise. (A) time course change, $x$ axis: elapsed time on running, $y$ axis: blood lactate concentration $(\mathbf{B})$ area under the curve of blood lactate acid, $x$ axis; group, $y$ axis: total volume of blood lactate. Values are expressed as mean \pm SE. $b$ : significant difference from pre $(p<0.01)$. n.s.: no significant differences.

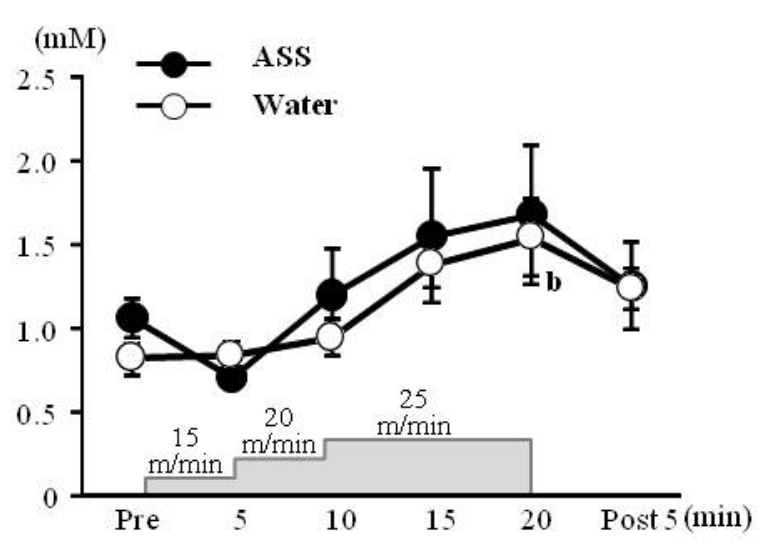

(A)

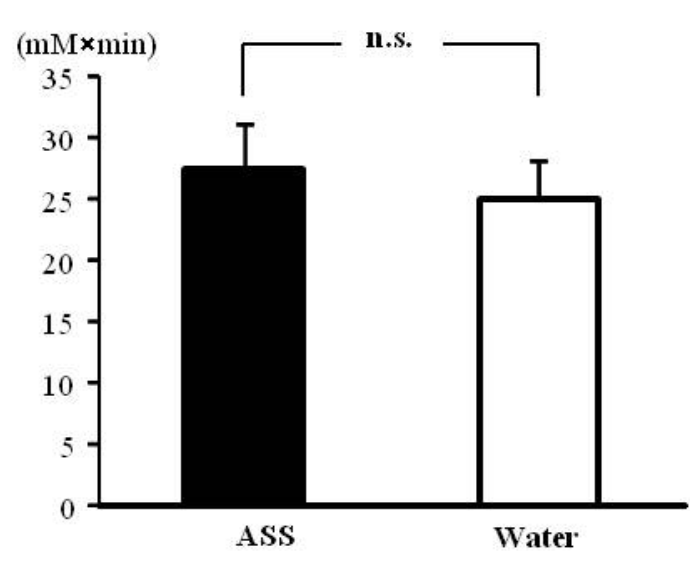

(B)

\subsection{Incremental Treadmill Running Test_Blood Glucose}

The results of 2-way ANOVA were $(F(1,31)=0.20, p=0.66, \operatorname{ES}(f)=0.08$, power $=0.08)$ for the condition (ASS vs. water), $(F(5,29)=3.53, p<0.05, \mathrm{ES}(f)=0.78$, power $=1.00)$ for the time course, and $(F(5,29)=0.46, p=0.80, \mathrm{ES}(f)=0.28$, power $=0.38)$ for condition $\times$ time course. No significant main effect or interaction was observed.

The blood glucose concentrations after administration of ASS were $65.33 \pm 6.67 \mathrm{mg} / \mathrm{dL}$ at rest, $55.00 \pm 5.00 \mathrm{mg} / \mathrm{dL}$ at $5 \mathrm{~min}$ after the start of exercise, $75.75 \pm 6.86 \mathrm{mg} / \mathrm{dL}$ at $10 \mathrm{~min}$ after the start of exercise, $81.25 \pm 5.71 \mathrm{mg} / \mathrm{dL}$ at $15 \mathrm{~min}$ after the start of exercise, $86.25 \pm 8.59 \mathrm{mg} / \mathrm{dL}$ at $20 \mathrm{~min}$ after the start of exercise, and $94.75 \pm 6.34 \mathrm{mg} / \mathrm{dL}$ at $5 \mathrm{~min}$ post-exercise. There was no significant change over the time course (Figure 2A). The values after administration of water were $73.50 \pm 13.40 \mathrm{mg} / \mathrm{dL}$ at rest, $68.67 \pm 10.68 \mathrm{mg} / \mathrm{dL}$ at $5 \mathrm{~min}$ after the start of exercise, $67.40 \pm 5.94 \mathrm{mg} / \mathrm{dL}$ at $10 \mathrm{~min}$ after the start of exercise, $81.40 \pm 8.49 \mathrm{mg} / \mathrm{dL}$ at $15 \mathrm{~min}$ after the start of exercise, $82.60 \pm 8.20 \mathrm{mg} / \mathrm{dL}$ at $20 \mathrm{~min}$ after the start of exercise, and $99.50 \pm 13.50 \mathrm{mg} / \mathrm{dL}$ at $5 \mathrm{~min}$ post-exercise. There was no significant change over in the time course (Figure 2A).

The AUC did not differ significantly between the ASS and control conditions $($ ASS: $1233.1 \pm 143.9(\mathrm{mg} / \mathrm{dL}) \times \min$, control: $1204 \pm 225.3(\mathrm{mg} / \mathrm{dL}) \times \min , p=0.892, \mathrm{ES}(d)=0.23$, power $=0.07)($ Figure $2 \mathrm{~B})$.

\subsection{Swimming Exercise Test-Blood Lactate Acid}

The results of 2-way ANOVA were $(F(1,8)=0.54, p<0.05, \mathrm{ES}(f)=0.59$, power $=1.00)$ for the condition (ASS vs. water) $(F(3,24)=13.17, p<0.01, \operatorname{ES}(f)=1.28$, power $=1.00)$ for the time course, and $(F(3,24)=2.47, p=0.09$, ES $(f)=0.56$, power $=0.88)$ for the condition $\times$ time course. Significant main effects were observed for both variables. 
Figure 2. Changes in the blood glucose on incremental treadmill exercise. (A) time course change, $x$ axis: elapsed time on running, $y$ axis: blood glucose concentration $(\mathbf{B})$ area under the curve of blood lactate acid, $x$ axis; group, $y$ axis: total volume of blood glucose. Values are expressed as mean \pm SE. n.s.: no significant differences.

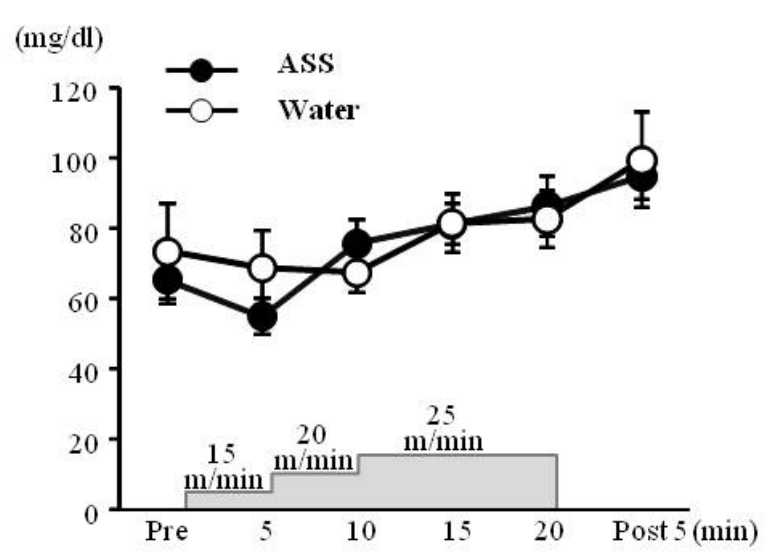

(A)

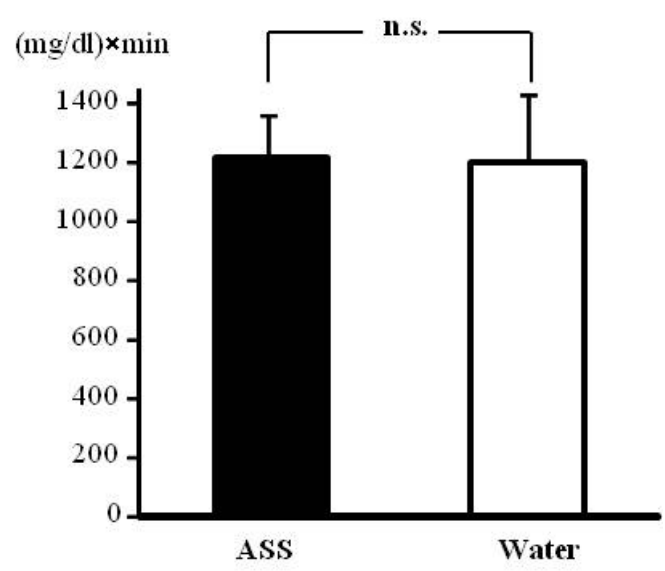

(B)

The blood lactate concentrations in the ASS group were $0.96 \pm 0.12 \mathrm{mM}$ at rest, $2.46 \pm 0.42 \mathrm{mM}$ at $10 \mathrm{~min}$ after the start of exercise, $2.06 \pm 0.66 \mathrm{mM}$ at $5 \mathrm{~min}$ of post-exercise and $2.16 \pm 0.61 \mathrm{mM}$ at $10 \mathrm{~min}$ post-exercise. There was no significant change over in the time course (Figure 3A). The values in the water group were $1.32 \pm 0.10 \mathrm{mM}$ at rest, $4.48 \pm 0.60 \mathrm{mM}$ at $10 \mathrm{~min}$ after the start of exercise, $4.60 \pm 0.73 \mathrm{mM}$ at $5 \mathrm{~min}$ of post-exercise, and $3.68 \pm 1.04 \mathrm{mM}$ at $10 \mathrm{~min}$ post-exercise. The blood lactate levels measured from $10 \mathrm{~min}$ after the start of exercise to $10 \mathrm{~min}$ post-exercise were significantly higher than the resting level (Figure 3A). Comparison between the two conditions at 5 min post-exercise revealed that the lactate level was significantly lower in the ASS group than in the control group (Figure 3A).

Figure 3. Changes in the blood lactate on swim exercise. (A) time course change, $x$ axis: elapsed time on swimming, $y$ axis: blood lactate concentration $(\mathbf{B})$ area under the curve of blood lactate acid, $x$ axis; group, $y$ axis: total volume of blood lactate. Values are expressed as mean \pm SE. a: significant difference from rest $(p<0.05)$. b: significant difference from rest $(p<0.01) . \Delta: p=0.053$. *: significant difference between ASS and control $(p<0.05)$.

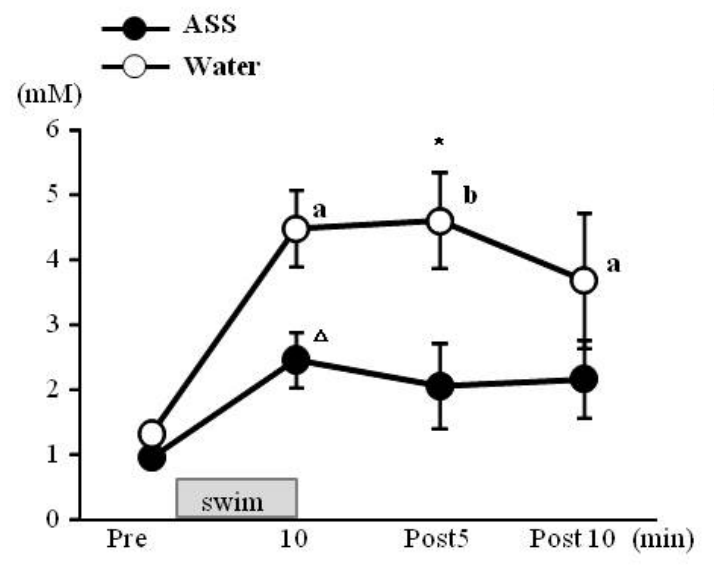

(A)

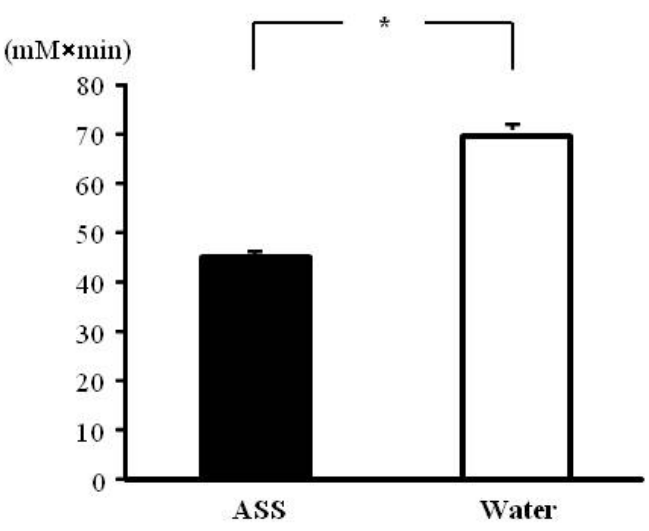

(B) 
The AUC was significantly lower in the ASS group than in the control group (ASS: $45.2 \pm 8.7 \mathrm{mM} \times \min$, control: $70.8 \pm 8.5 \mathrm{mM} \times \min$ ) (Figure $3 \mathrm{~B}$ ).

\subsection{Swimming Exercise Test: Blood Glucose}

The results of 2-way ANOVA were $(F(1,10)=0.52, p=0.52, \operatorname{ES}(f)=0.23$, power $=0.34)$ for the condition (ASS vs. water), $(F(3,30)=5.81, p<0.01, \operatorname{ES}(f)=0.76$, power $=0.99)$ for the time course, and $(F(3,30)=0.08, p=0.97, \mathrm{ES}(f)=0.09$, power $=0.07)$ for the condition $\times$ time course. A significant main effect of the time course was observed.

The blood glucose levels in the ASS group were $65.00 \pm 4.48 \mathrm{mg} / \mathrm{dL}$ at rest, $89.67 \pm 14.20 \mathrm{mg} / \mathrm{dL}$ at $10 \mathrm{~min}$ after the start of exercise, $95.50 \pm 12.09 \mathrm{mg} / \mathrm{dL}$ at $5 \mathrm{~min}$ post-exercise, and $78.17 \pm 8.02 \mathrm{mg} / \mathrm{dL}$ at $10 \mathrm{~min}$ post-exercise. The value was significantly higher $5 \mathrm{~min}$ post-exercise than at rest (Figreu 4A). The blood glucose levels in the control group were $69.17 \pm 4.48 \mathrm{mg} / \mathrm{dL}$ at rest, $99.83 \pm 16.83 \mathrm{mg} / \mathrm{dL}$ at $10 \mathrm{~min}$ after the start of exercise, $103.33 \pm 12.59 \mathrm{mg} / \mathrm{dL}$ at $5 \mathrm{~min}$ post-exercise and $90.00 \pm 9.27 \mathrm{mg} / \mathrm{dL}$ at $10 \mathrm{~min}$ post exercise. There was no significant change over the time course (Figure 4A).

Figure 4. Changes in the blood glucose on swim exercise. (A) time course change, $x$ axis: elapsed time on swimming, $y$ axis: blood glucose concentration $(\mathbf{B})$ area under the curve of blood lactate acid, $x$ axis: group, $y$ axis: total volume of blood glucose. Values are expressed as mean \pm SE. a: significant difference from rest $(p<0.05)$. n.s.: no significant differences.

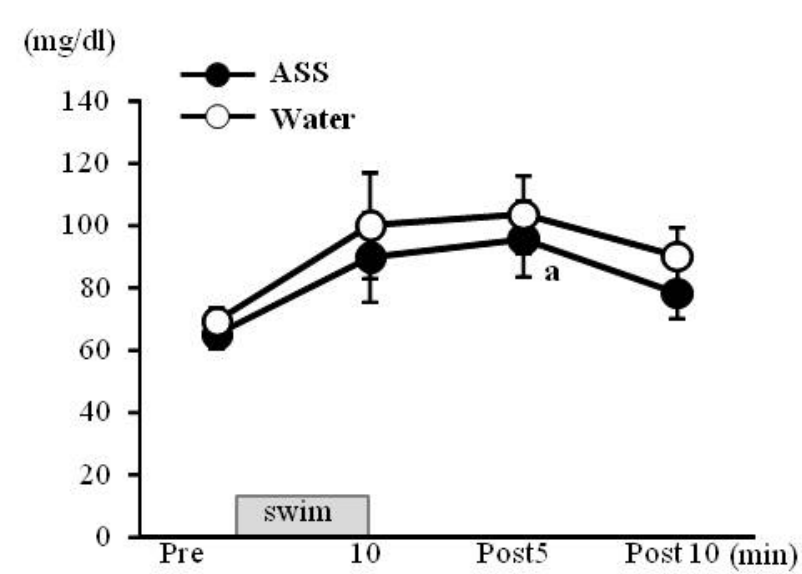

(A)

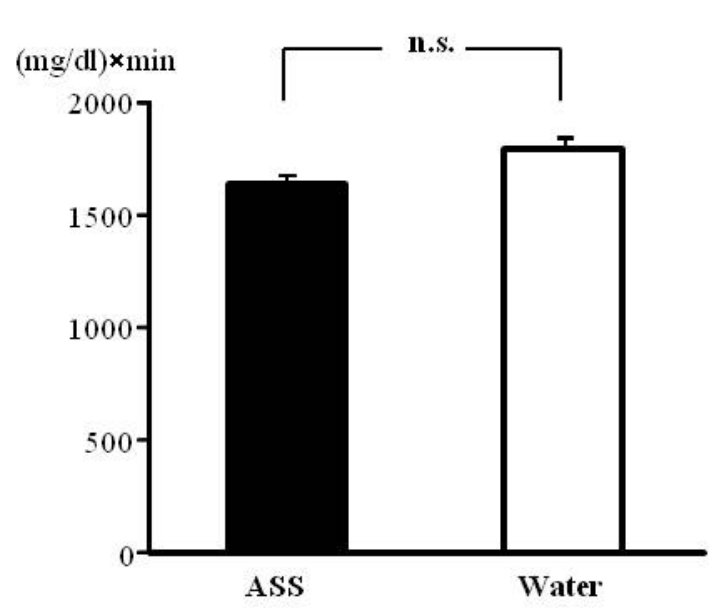

(B)

The AUC did not differ significantly between the ASS and control groups (ASS: $1670.7 \pm 188.1(\mathrm{mg} / \mathrm{dL}) \times \min$, control: $1836.3 \pm 174.4(\mathrm{mg} / \mathrm{dL}) \times \min , p=0.423, \operatorname{ES}(d)=0.37$, power $=0.09)($ Figure 4B).

\section{Discussion}

We investigated the anti-fatigue effects of $A$. sieboldianus by subjecting rats to exercise at several levels of intensity and found for the first time that $A$. sieboldianus intake before high-intensity exercise decreases the blood level of lactate, a substance generated during physical activity. This finding suggests 
that $A$. sieboldianus intake could help to alleviate fatigue during high-intensity exercise. Our result demonstrates a novel activity of $A$. sieboldianus in addition to its previously reported antioxidant and hyperglycemia-suppressing properties [4,5]. We infer that inhibiting blood lactate elevation during performing high-intensity exercise by ingesting this plant as a dietary supplement could suppress production of reactive oxygen species (ROS), improve metabolic capability, and prevent an excessive stress response.

We examined the effect of $A$. sieboldianus ingestion at various levels of exercise intensity and confirmed that the plant extract decreased the blood lactate concentrations during and after the swimming test, which represented high-intensity exercise. Lactate accumulation in the blood depends on the balance between lactate production by muscle activity and lactate removal by the liver and other tissues [14]. The glycolytic system is a major source of energy for the active muscles during high-intensity exercise, and the lactate accumulates when production outstrips removal. When lactate accumulates in the working muscles, the muscle hydrogen ion concentration increases and the $\mathrm{pH}$ decreases; furthermore, activation of phosphofructokinase, a rate-controlling enzyme in the glycolytic system, decreases, inhibiting the re-synthesis of ATP [15]. Consequently, muscle strength, which is necessary for high-intensity exercise becomes difficult as lactate accumulation leads to physical fatigue. In fact, previous studies have revealed that accumulation of lactate in the blood decreases endurance exercise performance [16]. In the current study, ingestion of $A$. sieboldianus before exercise reduced the blood lactate concentrations observed after high-intensity exercises in comparison with ingestion of water demonstrating an anti-fatigue effect of this herbal supplement.

The antioxidant function of $A$. sieboldianus has been suggested to underlie its inhibition of blood lactate level elevation. Previous reports have demonstrated an increased level of ROS during high-intensity exercise [17]. In addition, the blood lactate and ROS concentrations generated during exercise have been reported to correlate [18]. Another study found that ingestion of an antioxidant substance inhibited the production of ROS [19]. Although the details of the mechanism behind the correlation between the blood lactate and ROS levels remain unclear, we hypothesize that the antioxidant function of $A$. sieboldianus suppresses the increase in the blood lactate concentrations during high-intensity exercise.

Next, regarding the depressive action on blood lactate levels due to A. sieboldianus intakes may be relate to the efficiency of oxygen use and thus facilitating ATP re-synthesis [20]. Aguilo et al. [20] investigated the effect of antioxidant supplementation in amateur sportsmen and reported that carbon dioxide (CO2) excretion was elevated during high-intensity exercise (lactate threshold: $4 \mathrm{mM}$ ). During the acidotic state following high-intensity exercise, $\mathrm{CO} 2$ is eliminated into the exhaled breath to compensate for the metabolic acidosis. Because antioxidants can promote $\mathrm{CO} 2$ excretion during exercise, they may assist in the respiratory compensation for the acidotic state even during high-intensity exercise, and this presumably results in inhibition of lactate accumulation. The plasma volume might also have had an effect. As the intensity of exercise increases, the plasma volume declines. This reduction affects the osmotic pressure, the concentrations of electrolytes, and even the lactate level of the blood. In other words, because water or ASS consumption prior to exercise inhibited the reduction in plasma volume, increases in the blood lactate concentration in the present study were attenuated compared with previous studies. 
Finally, the suppression of the blood lactate concentration after ingestion of A. sieboldianus is likely to involve an anti-stress effect. The swimming tests used in our study subjected the rats to a great deal of psychological stress in addition to the exercise stress. In this study, the intake of ASS had no effect on the lactate and glucose concentrations during treadmill exercise. These findings suggest differences in the characteristics of the stressors involved in the two different types of exercise. In a study on exercise as an influence on stress hormones in horses, Alexander et al. reported that adrenocorticotropic hormone $(\mathrm{ACTH})$, stress hormone, secretion during running exercise is more related to increases in the arginine vasopressin (AVP) than to corticotrophin-releasing hormone (CRH) levels [21]. In contrast, a study by Jiang et al. demonstrated increased secretion of CRH $10 \mathrm{~min}$ after a swimming exercise [22]. In this study, at least 5 sessions of treadmill habituation were performed before treadmill running test. Therefore, the relatively modest increase in the blood lactate concentration may have been due to the absence of psychological stress, as the subjects become accustomed to treadmill exercise. Furthermore, the treadmill running in this study was estimated to correspond to approximately $70 \%$ of $\mathrm{VO}_{2 \max }$, i.e., mid-to-high-intensity exercise at just over the AT. However, this does not represent ultra-high-intensity exercise. This moderate intensity probably accounts for the relatively low blood lactate level produced. The swimming, by contrast, did not involve any practice analogous to the treadmill habituation and so presumably induced a greater stress reaction with substantial involvement of CRH in the ACTH secretion. Therefore, the current results suggest that ASS may be more effective against stress stimuli involving the secretion of $\mathrm{CRH}$ rather than AVP. A previous study in which Siberian ginseng (A. senticosus Harms), which, like A. sieboldianus, is a member of the Araliaceae family, was administered orally found an enhanced anti-stress effect attributed to activation of the noradrenaline system [23]. The $A$. sieboldianus used in our study may exert a similar anti-stress effect by suppressing the glycolytic mechanism induced by excessive sympathetic nervous system activation in response to physical and psychological stresses and thus inhibiting elevations of the blood lactate concentration.

\section{Conclusions}

We confirmed that administration of $A$. sieboldianus significantly decreases the blood lactate concentrations during and after high-intensity exercise relative to administration of water alone. This result suggests that ingestion of $A$. sieboldianus can help to alleviate fatigue during high-intensity exercise. In analyzing the mechanisms of this phenomenon, we assumed the potential involvement of all of the factors discussed above. Further investigation is necessary to determine whether all or only a single one of these factors are involved or whether the different mechanisms are related. It is also important to examine the other short-term effects of this herbal supplement as well as the effects of chronic administration in light of the results of this study.

\section{Acknowledgments}

We are deeply grateful to Yoshiyuki Akiba of Otamaya Ltd. for a supply of the dry powdered of Acanthopanax sieboldianus leaf. We also gratefully acknowledge the valuable comments of Ching-Liang Lu at Division of Gastroenterology, Taipei Veterans General Hospital and National Yang-Ming University. 
This work was supported by Yonezawa Women's Junior College Grant-in Aid for Collaborative Research Projects and supported by a special grant from Seoul Women's University (2013).

\section{Conflicts of Interest}

The authors declare no conflict of interest.

\section{References}

1. American College of Sports Medicine Position Stand. The recommended quantity and quality of exercise for developing and maintaining cardiorespiratory and muscular fitness, and flexibility in healthy adults. Med. Sci. Sports Exerc. 1998, 30, 975-991.

2. Brug, J.; Lien, N.; Klepp, K.I.; van Lenthe, F.J. Exploring overweight, obesity and their behavioural correlates among children and adolescents: Results from the Health-promotion through Obesity Prevention across Europe project. Public Health Nutr. 2010, 13, 1676-1679.

3. Heller, T.; McCubbin, J.A.; Drum, C.; Peterson, J. Physical activity and nutrition health promotion interventions: What is working for people with intellectual disabilities? Intellect. Dev. Disabil. 2011, 49, 26-36.

4. Tabuchi, M.; Tamura, A.; Matsuba, S.; Onodera, J.; Yamada, N. Inhibitory effects of ukogi (Acanthopanax sieboldianus) leaves on postprandial blood glucose elevation in rats. J. Jpn. Soc. Nutr. Food Sci. 2004, 57, 271-275.

5. Yamada, N.; Tamura, A.; Tabuchi, M. Composition characteristics and antioxidative activity of ukogi (Acanthopanax siebldianum). Bull. Yamagata Prefect. Yonezawa Women's Jr. Coll. 2003, 38, 1-6 (in Japanese).

6. Panossian, A.; Wagner, H. Stimulating effect of adaptogens: An overview with particular reference to their efficacy following single dose administration. Phytother. Res. 2005, 19, 819-838.

7. Fujikawa, T.; Yamaguchi, A.; Morita. I.; Takeda, H.; Nishibe, S. Protective effects of Acanthopanax senticosus Harms from Hokkaido and its components on gastric ulcer in restrained cold water stressed rats. Biol. Pharm. Bull. 1996, 19, 1227-1230.

8. Zhang, X.L.; Ren, F.; Huang, W.; Ding, R.T.; Zhou, Q.S.; Liu, X.W. Anti-fatigue activity of extracts of stem bark from Acanthopanax senticosus. Molecules 2011, 16, 28-37.

9. Norton, K.; Norton, L.; Sadgrove, D. Position statement on physical activity and exercise intensity terminology. J. Sci. Med. Sport 2010, 13, 496-502.

10. Mazzeo, R.S.; Marshall, P. Influence of plasma catecholamines on the lactate threshold during graded exercise. J. Appl. Physiol. 1998, 67, 1319-1322.

11. Podolin, D.A.; Munger, P.A.; Mazzeo, R.S. Plasma catecholamine and lactate response during graded exercise with varied glycogen conditions. J. Appl. Physiol. 1991, 71, 1427-1433.

12. Chang, H.; Saito, T.; Ohiwa, N.; Tateoka, M.; Deocaris, C.C.; Fujikawa, T.; Soya, H. Inhibitory effects of an orexin-2 receptor antagonist on orexin A- and stress-induced ACTH responses in conscious rats. Neurosci. Res. 2007, 57, 462-466. 
13. Chang, H.; Park, J.; Suk, M.; Lee, H.; Kang, H.; Choi, K.; Song, W. Comparison of lactate threshold, glucose, and insulin levels between OLETF and LETO rats after all-out exercise. J. Sports Sci. Med. 2009, 8, 381-387.

14. Stanley, W.C.; Gertz, E.W.; Wisneski, J.A.; Morris, D.L.; Neese, R.A.; Brooks, G.A. Systemic lactate kinetics during graded exercise in man. Am. J. Physiol. 1985, 249, E595-E602.

15. Baker, J.S.; McCormick, M.C.; Robergs, R.A. Interaction among skeletal muscle metabolic energy systems during intense exercise. J. Nutr. Metab. 2010, 2010, 1-13.

16. Sjödin, B.; Jacobs, I. Onset of blood lactate accumulation and marathon running performance. Int. J. Sports Med. 1981, 2, 23-26.

17. Viña, J.; Gimeno, A.; Sastre, J.; Desco, C.; Asensi, M.; Pallardó, F.V.; Cuesta, A.; Ferrero, J.A.; Terada, L.S.; Repine, J.E. Mechanism of free radical production in exhaustive exercise in humans and rats; role of xanthine oxidase and protection by allopurinol. IUBMB Life 2000, 49, 539-544.

18. Sastre, J.; Asensi, M.; Gascó, E.; Pallardó, F.V.; Ferrero, J.A.; Furukawa, T.; Viña, J. Exhaustive physical exercise causes oxidation of glutathione status in blood: Prevention by antioxidant administration. Am. J. Physiol. 1992, 263, R992-R995.

19. Zembron-Lacny, A.; Szyszka, K.; Sobanska, B.; Pakula, R. Prooxidant-antioxidant equilibrium in rowers: Effect of a single dose of vitamin E. J. Sports Med. Phys. Fitness 2006, 46, 257-264.

20. Aguiló, A.; Tauler, P.; Sureda, A.; Cases, N.; Tur, J.; Pons, A. Antioxidant diet upplementation enhances aerobic performance in amateur sportsmen. J. Sports Sci. 2007, 25, 1203-1210.

21. Alexander, S.L.; Irvine, C.H.; Ellis, M.J. The effect of acute exercise on the secretion of corticotropin-releasing factor, arginine vasopressin, and adrenocorticotropin as measured in pituitary venous blood from the horse. Endocrinology 1991, 128, 65-72.

22. Jiang, Y.-Q.; Kawashima, H.; Iwasaki, Y.; Uchida, K.; Sugimoto, K.; Itoi, K. Differential effects of forced swim-stress on the corticotropin-releasing hormone and vasopressin gene transcription in the parvocellular division of the paraventricular nucleus of rat hypothalamus. Neurosci. Lett. 2004, $358,201-204$.

23. Soya, H.; Deocaris, C.C.; Yamaguchi, K.; Ohiwa, N.; Saito, T.; Nishijima, T.; Kato, M.; Tateoka, M.; Matsui, T.; Okamoto, M.; et al. Extract from Acanthopanax senticosus harms (Siberian ginseng) activates NTS and SON/PVN in the rat brain. Biosci. Biotechnol. Biochem. 2008, 72, 2476-2480.

(C) 2013 by the authors; licensee MDPI, Basel, Switzerland. This article is an open access article distributed under the terms and conditions of the Creative Commons Attribution license (http://creativecommons.org/licenses/by/3.0/). 